ENABLING ENGAGEMENT: AN EXPLORATION OF ACCESSIBILITY PLANNING FROM BERLIN TO TORONTO

\author{
by \\ Jacky Hao-Kit Li \\ HBA, University of Toronto, 2014 \\ A Major Research Paper \\ presented to Ryerson University \\ in partial fulfillment of the requirements for the degree of \\ Master of Planning \\ in \\ Urban Development
}

Toronto, Ontario, Canada, 2016

(C) Jacky Hao-Kit Li 2016 


\section{AUTHOR'S DECLARATION FOR ELECTRONIC SUBMISSION OF A MRP}

I hereby declare that I am the sole author of this MRP. This is a true copy of the MRP, including any required final revisions.

I authorize Ryerson University to lend this MRP to other institutions or individuals for the purpose of scholarly research

I further authorize Ryerson University to reproduce this MRP by photocopying or by other means, in total or in part, at the request of other institutions or individuals for the purpose of scholarly research.

I understand that my MRP may be made electronically available to the public. 


\title{
ENABLING ENGAGEMENT: AN EXPLORATION OF ACCESSIBILITY PLANNING FROM BERLIN TO TORONTO
}

\author{
(C) Jacky Hao-Kit Li, 2016 \\ Master of Planning \\ in \\ Urban Development \\ Ryerson University
}

\begin{abstract}
The Accessibility for Ontarians with Disabilities Act (AODA) is a landmark piece of legislation that removes both physical and social barriers faced by people with disabilities. This Act will make Ontario fully accessible to people with disabilities by 2025 through the development of accessibility standards, all while changing the perceptions of accessibility and people with disabilities. This research paper will explore accessibility planning in Toronto. Given that planners work in communicative roles, there is little direction in AODA that discuss engagement activities. Planners must utilize a mix of high- and low-tech methods when engaging with vulnerable communities, especially with people with disabilities. A case study of methods and planning policies in Berlin, Germany is presented to illustrate strong efforts in designing barrier-free spaces. Examples from Berlin will be then compared to Toronto's efforts in addressing issues of accessibility and engagement with people with disabilities.
\end{abstract}

Key words: accessibility; urban planning; engagement; technology; Accessibility for Ontarians with Disabilities Act 


\section{ACKNOWLEDGEMENTS}

First and foremost, I would like to thank my supervisor, Dr. Zhixi C. Zhuang, for her guidance, encouragement, enthusiasm, and patience. Her constructive comments allowed this research paper to become stronger. Her positive attitude and reinforcement greatly assisted me in the preparation of this project.

I would also like to thank my second reader, Dr. Pamela Robinson, for her invaluable insight on all things planning, engagement, and tech. I am grateful for her critiques and comments for this research paper.

To my friends and family, I want to sincerely thank you for your positive support and patience as well. You've watched me struggle; now you will watch me succeed. I owe you guys some quality time and many beverages. 


\section{Table of Contents}

AUTHOR'S DECLARATION FOR ELECTRONIC SUBMISSION OF A MRP II

ABSTRACT III

ACKNOWLEDGEMENTS IV

LIST OF FIGURES $\quad$ VI

LIST OF APPENDICES $\quad$ VI

INTRODUCTION

RESEARCH QUESTION + OBJECTIVES

CONTRIBUtIONS TO PLANNING PRACTICE

METHOD $\quad 6$

$\begin{array}{lr}\text { RESEARCH LIMITATIONS } & 7\end{array}$

LITERATURE REVIEW $\quad 8$

THE STATE OF CONTEMPORARY CIVIC ENGAGEMENT

PLANNING IN THE CONTEXT OF TORONTO, CANADA 13

ACCESSIBILITY PLANNING IN TORONTO

UNIVERSAL DESIGN AND THE AGING POPULATION 19

SUMMARY OF LITERATURE REVIEW $\quad 20$

CASE STUDY: BERLIN, GERMANY $\quad 21$

\begin{tabular}{lr} 
KEY FINDINGS & 29 \\
\hline
\end{tabular}

\begin{tabular}{ll} 
APPLICATION TO TORONTO & 30 \\
\hline
\end{tabular}

RECOMMENDATIONS $\quad 32$

$\begin{array}{ll}\text { CONCLUSION AND AREAS FOR FURTHER RESEARCH } & 37\end{array}$

APPENDICES $\quad 40$

APPENDIX A: PATH TO 2025 FACT SHEET 40

APPENDIX B: OVERVIEW OF UPDATED ACCESSIBILITY REQUIREMENTS 41

APPENDIX C : OVERVIEW OF THE LEGAL FRAMEWORK IN BERLIN

REFERENCES $\quad 46$ 


\section{LIST OF FIGURES}

Figure I - Ontario's Policy-Led Planning System in the Context of Toronto

Figure II - Screenshot of Mobidat

Figure III - Detail of Tactile Features of the Talking City Model

Figure IV - The Talking City Model

Figure V - Photograph from the Hack-cessibility event. Photo by Brookfield Institute

\section{LIST OF APPENDICES}

Appendix A: Path to 2025 Fact Sheet

Appendix B: Overview of Updated Accessibility Requirements

Appendix C: Overview of the Legal Framework in Berlin 


\section{INTRODUCTION}

This research paper will explore how planners are engaging with people with disabilities in planning for accessibility in Toronto, Canada. The paper will look to Berlin, Germany, as a case study because of their strong government policies on building barrier-free spaces, which led to a shift in the culture of development in the city. Since Toronto is under the Province of Ontario's policy-led planning system, it is subjected to the Accessibility for Ontarians with Disabilities Act (AODA), a legislative mandate that sets accessibility standards across the province. The intention of AODA is to not only create a fully accessible Ontario for all, but to promote a cultural shift in the attitudes towards disabilities, and people with disabilities. AODA affects planning since it shapes the way government communications are designed, dictates how buildings and public space are designed, and requires accessible transportation options. There is, however, little on how to engage with people with disabilities in the planning process. This paper will look to examples of how practitioners have filled that gap using both conventional and non-conventional engagement efforts.

As part of AODA's suite of public awareness campaigns, the Province of Ontario hosted its first Accessibility Innovation Showcase and Tech Pitch Competition at Toronto's MaRS Discovery District, in August 2015. The showcase was made organized through a partnership between Ministry of Economic Development, Employment and Infrastructure (MEDEI) and the Ontario Centres of Excellence (OCE). This innovation showcase offered Ontario-based businesses a chance to connect with potential investors to further develop their ideas or products. The products showcased at the event were focused on accessibility and assistive technology, which included exoskeletons, prosthetics, robotics, wearable technology, and mobile apps. The Accessibility Innovation Showcase also featured a speaker series as well as a hack-athon where the winners were awarded $\$ 20,000$ to help with the development of their business idea. The purpose of the showcase was to encourage investment in 
accessibility and tech industry and provide networking opportunities for this creative industry.

The Accessibility Innovation Showcase was a way for the Province of Ontario to promote a cultural shift on the attitudes towards accessibility and people with disabilities. Public attendees were given the chance to see and try the different types of assistive devices and technologies being designed and developed by companies in Ontario. The winner of the Accessibility Tech Pitch competition was a Toronto-based social enterprise company, LegWorks, and they developed a low cost, highperformance prosthetic knee. Upon winning, LegWorks announced that they would use the prize money to fit 200 amputees in developing countries (OCE, 2015, para. 1). The convergence of the tech industry with the dialogue around accessibility is notable because as new technological innovations become more accessible, individuals are now able to be exposed to new and affordable applications and solutions compared to the past.

This showcase took place in conjunction with the Toronto 2015 Pan Am/Parapan Am Games, which was hosted in Canada for the first time. The Parapan Am Games took place in August 2015, after the Pan Am Games. This portion of the games was focused on para-athletics - sports for people with disabilities. The Parapan Am Games' mission statement is about "elevating the Paralympic Movement both locally and globally, as well as showcasing accessibility" (Toronto 2015 Pan Am/Parapan Am Games, 2015, para. 6). The discourse on accessibility is quickly drawing mass attention and exposure because of big events like the Pan Am/Parapan Am Games, but also because government policies and people's mentalities are now recognizing the issues of accessibility and benefits of universal design.

As Kevin Shaw (2014), founder Zagga Entertainment, said, "People aren't disabled, its the environment that's disabling". On June 13, 2005, the Accessibility for Ontarians with Disabilities Act (AODA) became law. This Act mandates the implementation of accessibility standards across Ontario by the end of 2025 under five 
categories: customer service, employment, information and communications, transportation, and design of public spaces, in efforts to prevent and remove barriers that people with disabilities face in daily living in Ontario. These standards apply to both public and private organizations. With this Act, Ontario becomes "the first jurisdiction in the world to require staff to be trained on accessibility" (Government of Ontario, 2015, p. 2). This landmark legislation dictates that Ontario will be fully accessible to people with disabilities by 2025 through the development of accessibility standards, and enforcement of the standards, all while changing the mentality and culture around discussions about accessibility and people with disabilities. According to the Government of Ontario (2015) 1 in 7 Ontarians have some form of disability; AODA will help these Ontarians access their communities and employment opportunities in order to create an equitable and improved quality of life for all.

Disability includes a wide breadth of impairments and can be both visible and non-visible. Generally speaking, as the population continues to get older, the number of people with disabilities increases as well. According to the Government of Ontario (2015, p. 3), "Ninety per cent of Canadians believe that people with disabilities are not fully included in society". Given this fact, surely there are new and more innovative methods in engaging people with disabilities in the urban planning process.

The remarkable difference in contemporary society compared to the past is our connectivity to information and connectivity technologies (ICT). ICT is a blanket term that covers the convergence of communication networks (telecommunications, television, and other audio visual) with computer networks, which were once separate concepts and/or products (Technopedia, n.d.). These unified communications include, and are not limited to: computers, smart phones, software, hardware, and things connected to the Internet (Technopedia, n.d.). Typically, technology in the planning practice was mainly used for geographic information systems (GIS) and other quantitative data analysis. Today, however, we have all these innovative interactive elements and applications that can help planners to engage broader audiences. Information and communications technologies is not the silver bullet that will solve all 
public engagement and/or wicked planning problems, but it is an additional tool for the planner's toolkit to engage better.

It is important to explore ICT in planning because ICT has the potential to bring about a more inclusive planning process. When planners use tools like the Internet, engagement activities have the ability to reach disenfranchised or underrepresented communities. The goal is to create an inclusive and accessible process, and ICT can do that. There are, however, limitations and barriers to accessing or using digital tools such as digital literacy or availability and access to services or technology among other factors. Those debates are outside of the discussion in this document. This paper will focus on planners how planners use different technologies in engaging people about accessibility.

\section{Research Question + Objectives}

The research question explored in this paper asks: how are planners using information and communications technology to engage with people with disabilities? The paper will show planners that new technologies have created new avenues for better engagement in planning for accessibility and universal design. Universal design is the design of both physical and non-physical environments as well as products that are inclusive to the user regardless of mental or physical ability (Mace, 1998). Planners will be able to create better spaces when they engage with the affected population early in the process. In doing so, public engagement holds the potential to build meaning partnerships with community members and organizations while building awareness along the way.

To do so, this paper will look at ways different levels of government have leveraged strategic partnerships with Toronto's creative industries to accelerate the dialogue on accessibility in the city. The policies and initiatives in Toronto will be compared to Berlin, Germany, which is a city that has previously won the European Union's Access City Award - an award that recognizes cities that make space more accessible by people with disabilities and elderly. 


\section{Contributions to Planning Practice}

The first responsibility in the Ontario Professional Planners Institute's (OPPI) Professional Code of Practice is the planner's responsibility to the public interest. Thus, as planners our first responsibility is to the public - we need to effectively engage people in planning issues. The cohort that is often overlooked are people with disabilities. The now-mandated AODA standards will bring inclusivity into the process. The standards, however, mainly dictate how buildings are built, how space is designed, and how information is communicated.

This paper will look at how planners utilize both traditional and new media applications to engage with people with disabilities in planning for universally accessible spaces and explore the implications of the Accessibility for Ontarians with Disabilities Act on planning practice. 


\section{METHOD}

Accessibility helps more than just people with disabilities. Benefits of universal design are enjoyed by everyone including the elderly, young children, and even people schlepping large baggage. Contemporary society has reached a critical point in innovation with the collaborative cultures surrounding open source technologies, 3D printing, and the do-it-yourself community. This paper will explore how collaboration between governments and the creative industries are helping to create universally designed spaces with and for people with disabilities. To do so, this paper will look at ways the Ontario government has leveraged strategic partnerships with Toronto's creative industries to accelerate the dialogue on accessibility in the city. The initiatives in Toronto will be compared to Berlin, Germany, a city that has previously won the European Union's Access-City Award.

The research method used in this exploration is content analysis of secondary sources. As described by Neuman (2007), "[c]ontent analysis is a technique for gathering and analyzing the content of text ... [where text] is anything that serves as a medium for communication (p. 227). The key sources used to explore this topic discussed include: government policy documents, books, newspapers, magazines, academic journals, Internet videos and other official planning-related documents.

This paper begins with a literature review of both academic and grey literature in order to establish themes for analysis throughout the paper. The key themes of this paper are accessibility, public engagement, and new technology. The literature review then goes into a policy scan of current mandates that pertain to planning and accessibility in Toronto, Ontario, Canada. From there, a case study of Berlin, Germany will be presented to outline their planning and accessibility framework that governs their development and planning processes.

Berlin was chosen to be a case study because of its accomplishments in creating barrier-free spaces and strong accessibility policies. Berlin was also the winner of the Access-City Award in 2013 - an award that recognizes European cities that make 
space more accessible by people with disabilities and elderly. Berlin was recognized for this award because of their online engagement efforts with people with disabilities as well as their strong planning policies that govern development in the city. The Senate Department for Urban Development and the Environment also hosts a permanent collection of city models with an extensive section for planning barrier-free access and spaces.

From the case study of Berlin, literature review, and policy scan, key findings from the successes will emerge. These findings will then be applied to the context of Toronto in order to explore the opportunities that are currently present in the city in terms strategies and collaborations. Finally, the paper will end with recommendations on the next steps for planning practitioners and researchers.

\section{Research Limitations}

This research paper is limited the content analysis of academic and grey literature on matters related to public engagement and accessibility, as well as government policy documents from Canada, Germany, and the European Union. In terms of literature from and about Berlin, Germany, the research here is limited to only publications that are available in English. The research does not involve human participants for opinions or to justify findings.

Ultimately, this research paper is envisioned to be a starting point for a greater discourse on public engagement with people with disabilities, as there is currently limited literature on the matter that is grounded in planning practice. Going forward, research in the realm of urban planning, public participation, and engagement with people with disabilities should consider face-to-face interviews with planners and people with disabilities in order to establish context and opinion about such matters. Research should also look into cataloging results of engagement activities that specifically targeted people with disabilities and evaluate the outcomes of planning decisions made from those initiatives. 


\section{LITERATURE REVIEW}

\section{The State of Contemporary Civic Engagement}

Public participation has not always been a significant part of the planning practice. Planning had humble roots in public health. At its inception, planning was needed and utilized to address public health concerns of the great towns - as described by Friedrich Engels, where he takes readers on a tour of the working-class settlements and conditions in Manchester, England, at the height of the Industrial Revolution (LeGates and Stout, 2011). The unplanned industrial manufacturing city has no sewage systems or ventilation, which poses many health concerns to the working class (LeGates and Stout, 2011a, p. 53). The origins of urban planning can be traced back to these great or industrial towns where there was a need for organizing growth in order to provide healthy living conditions for residents. At this time, the idea was that you could fix cities and its plights using the urban design concepts of Ebenezer Howard's garden cities (LeGates and Stout, 2011b) and Frederick Law Olmstead's public parks (LeGates and Stout, 2011c).

Planning then went through a phase after World War III where it became scientifically calculated and standardized. This was modern era in planning is a reaction to the previous epoch. Planners now focused on promoting health and well being for all residents rather than building monumental parks for the upper echelon; social needs are now more considered than individual needs. There was a belief here that science and the scientific method can solve collective social problems. This comprehensive rationality utilized science in planning by heavily investing faith in the standardization and specialization.

In urban development, this took the form of specialized zoning districts connected by large freeways to optimize efficiency. The modern era is characterized by suburban expansion, large social housing projects, and faith in technology and science. What was seen as solutions at the time actually could not address the unique and complex urban problems, or wicked problems as Rittel and Webber (1973) suggests. 
Contemporary planning practice, however, has become more mindful of the users of urban space, their experiences of space, and the planning process. Whereas in the modern era, planners we seen as the technical experts or specialists, postmodern planning has added new responsibilities to planners such as the role of the facilitator and/or communicator. In this new communicative age, planners must now foster good communications that is jargon-free and undistorted (Forester, 1989). Modern planning was functional, technical, and based on science, and postmodern planning now relies on dialogue, observation, and interpretation. Contemporary planning theory recognizes complex societal problems and focuses on communication with participants and leveraging local knowledge in order to fix problems rather than prescribing a remedy. Public participation is now the vanguard of contemporary planning.

What had originally started as a planning for people mindset, we are now planning with people. Urban renewal, freeway construction, and civil rights movements in the 50 s and 60 s largely fueled the postmodern planning practice that now features public involvement at the forefront. These experiences were discussed in Jane Jacob's (1961) seminal book, The Death and Life of Great American Cities. Today, there is an expectation from the public to participate in planning issues, and planners are now under more pressure to incubate public involvement in decision-making processes. Traditional consultation processes, however, are not immune to problems or controversy either. In planning, the traditional means of engagement are public hearings. These are formally recognized by law, but are not very practical, as these processes tend to bring out specific motivated audiences that are not representative the community's broader demographic. With these ideally democratic forums, structures of power often manipulate the debate as described in Flyvbjerg (1998) and Forester (1989). Even when public participation is legally required, Innes and Booher (2004) state that public hearings do not work since they do not often improve decisions, and often pits citizen against one another (p. 419). Also, public hearings often do not bring out a broad spectrum of the public (Innes and Booher, 2004, p. 419). 
With citizen participation being at the forefront of contemporary planning practice, the levels of participation across the practice however, are not universal. The level of citizen participation varies, as critiqued in Arnstein's (1969) work, A Ladder of Citizen Participation. Arnstein (1969) suggests the idea that citizen participation can be visualized as a ladder of participation, where at the bottom of the ladder are nonparticipants, in the middle are varying degrees of tokenism, and at the top of the ladder are varying degrees of citizen power. The ladder is representative of the degrees of power citizens have: less at the bottom and more powers of influence at the top.

Tokenism is the effort of including underrepresented groups into decision-making processes; however, the efforts do not provide meaningful opportunities for the groups to fully participate or to have impactful means of control on the process. Tokenism is the act of including an underrepresented group for the sake of showing that the process is inclusive without having to relegate meaningful engagement opportunities. People with disabilities often fall victim to different tokenistic processes as discussed in Hutton et al. (2010).

Meanwhile, the connectivity of information and communications technologies holds potential to create better, more meaningful engagement between planners and the public; perhaps to reach a higher level in the ladder of participation. Planners are now increasingly incorporating the use of ICT into their engagement initiatives. Planning practitioners can now turn to the Internet for research and outreach through databases, forums, social media, and other means. Online participation can allow planners to reach more people in shorter amounts of time, often times at lower cost. Content and delivery can be targeted for specific underrepresented demographics in order to obtain a more diverse mixture of participants. With the social networking components of ICT, these new media applications can "connect citizens to each other in order to set local priorities, support community activism, facilitate collaboration, and help foster knowledge and local problem-solving" (Mather, 2014, p. 7-8). 
Innes and Booher (2004) suggest that good participation needs to incorporate not only citizens, but also a diverse, cross sector mixture of perspectives in order for citizens to co-evolve (p. 422). The broad spectrum of participants will allow for social learning as concepts and ideas are shared among participants. The collaborative dialogue should not be reactive, but should look forward and anticipate future actions (Innes and Booher, 2004, p. 422). ICT can help planners to bridge the gap of the underrepresented populations by making information more accessible to wider audiences as well as creating new applications tailored for the end-user so that the information is effectively received. As it is one of Innes and Booher's (2004) purposes of participation, advancing fairness and justice is the reason why participation needs to be accessible and inclusive.

Technology is creating avenues for democratizing design when people collaborate (Fischer, 2011). Universal design, also known as inclusive design, is the idea that products, buildings, or access, when designed properly, can be used by people with or without disabilities or impairments. It is essentially a design for all mentality. Universal design creates accessible experiences when done effectively, which will remove the barriers to access. The discourse on assistive technology is a growing field as tech developers continue being more and more experimental and inventive (as presented at the Accessibility Innovation Showcase). In planning practice, however, technology being utilized is mainly for online and digital engagement.

The most challenging part of public engagement is reaching the most vulnerable and disadvantaged (Biggs, 2013). Online engagement will not solve all engagement problems, but it can expand the reach of engagement activities to a broader spectrum of the community. A good digital engagement initiative is inclusive. Fischer (2011) stresses, "not every participant must contribute, but all participants must have opportunities to contribute when they want to" (p. 48). Fischer (2011), Biggs (2013), and PlaceMatters (2014) all identify that engagement efforts that combine both digital tools and face-to-face interactions are successful in engaging with vulnerable and/or underrepresented populations. Interestingly, the PlaceMatters (2014) report notes that 
the planning practitioners they interviewed from the United States who worked closely with low-income communities and communities of colour do not use technological tools; rather they discovered that face-to-face interactions are more effective (p.13).

The International Telecommunication Union (ITU) is a special agency of the United Nations that studies the research and development of information and communications technologies. The ITU (2013) published a report titled The ICT Opportunity for a Disability-Inclusive Development Framework that highlighted "the extent to which information and communication technologies (ICTs) enable and accelerate the social and economic inclusion of persons with disabilities" (p. ix). In this report, the ITU (2013) identified that "[o]verall, web services (and the devices used to access them) constitute the access technology with the greatest impact in promoting the inclusion of persons with disabilities ... followed by mobile phones" (ITU, 2013, p. 6).

The accessibility and digital engagement discourse, however, are largely around the design of webpages. Some typefaces, font sizes, and colour combinations are problematic to people with or without vision impairment, as the information can be difficult to read. Today's interactive elements and highly visual features do not work well with screen readers and other assistive technologies. The solution to this, which many organizations have implemented already, is to create web accessibility design guidelines - which dictate typefaces, font sizes, and colour combinations. Fischer (2011) claims that there is a substantial portion of assistive technology users who abandon the product after the initial purchase (p. 50). Often, design guidelines may not be helpful for people with disabilities; engagement activities should also offer options for person-to-person interaction.

When planners use information and communications technology in for public engagement, it can solve some problems in participation, but not all of them. It is recommended that practitioners use a multi-faceted strategy that utilizes both digital engagement and face-to-face events (Biggs 2013, PlaceMatters 2014). When engaging with vulnerable and under represented populations, the best practice is to use a mixed 
method approach that uses many forms of communications in order to reach more people from a broader demographic. It cannot be stressed enough that practitioners must identify and understand the audience when doing engagement activities. Mather (2014) states, "Digital engagement tools have also been integrated slowly because of concerns around data ownership, data quality, reliability, privacy and confidentiality, and other legal and ethical issues" (p. 10). The potential for innovation, however, lays in utilizing new media technology for engagement with people with disabilities.

\section{Planning in the context of Toronto, Canada}

Planning in Toronto is framed different levels of governments. Figure I shows Ontario's policy-led planning system in the context of Toronto. The Government of Ontario writes the Planning Act, which gives powers to municipalities to write their own official plans according to a list of provincial interests called the Provincial Policy Statement. From there, municipal official plans have to conform to applicable provincial plans and documents.

In Toronto, public participation is legally mandated in Ontario's Planning Act. Under this legislation, the public is entitled to receive notice of development applications. This includes public meetings and open houses regarding official plan amendments, zoning by-laws amendments, and plans of subdivision. The public also has the right to access information with respect to the proposal (section 1.0.1), the right to be heard, as well as opportunities to appeal decisions. Public consultation must occur over during the preparation of the plan (section 15).

The Planning Act also dictates how official notice is presented. Legally, notice must take the form of signage on the property, publication in a newspaper of general circulation, and by mail. On December 3, 2015, the Planning Act had been amended to include e-mail as official notice. In Ontario's policy-led planning system, Legislation only declares how notice is and that community consultation is required; there is no document that stipulates how community consultations occurs. 
Planning Act

Provincial Policy Statement

Provincial Plans:

Growth Plan for the Greater Golden Horseshoe

Single-Tier Official Plans:

Toronto Official Plan

Community Improvement Plans

Development Permit System, Zoning By-Law,

Site Plan Control, and Minor Variance

Figure I - Ontario's Policy-Led Planning System in the Context of Toronto

There are, however, supplementary documents published by different levels of government and organizations that suggest how to facilitate community consultations to be made accessible and barrier-free. For instance, the Ontario Municipal Social Service Association created the Guide to Accessible Public Engagement and the Guide to Conducting Accessible Meetings. The Government of Ontario has Guidelines for Barrier-free Design of Ontario Government Facilities. And the City of Toronto has its own Accessibility Design Guidelines. The most substantive document, and enforceable piece of legislation, on accessibility standards is the Accessibility for Ontarians with Disabilities Act (AODA). 


\section{Accessibility Planning in Toronto}

Accessibility planning in Toronto is regulated through a few levels of government. There is the Accessible Design for the Built Environment, which is a voluntary design guideline published by Canadian Standards Association that is generally seen as more comprehensive than the Ontario Building Code, but is lacking substantive depth in discussing way finding, accessible signage, and fire and health safety (Paquette and Rogojine, 2015). Next is the Ontario Building Code, which sets the technical requirements and regulations for new buildings, additions, renovations and repairs. In 2015, the Building Code was amended as a part of the Accessibility for Ontarians with Disabilities Act to include requirements for accessible parking, entrances, ramps and stairs, elevators, washrooms, routes, signs, and exits. The final layer of accessibility policy is found in municipal design guidelines and best practices. Municipalities are able to create their own design guidelines as a way of offering design advice and expertise in development.

The Accessibility for Ontarians with Disabilities Act (AODA) is the most powerful force behind accessibility planning in Toronto. AODA created mandatory accessibility standards in efforts to prevent and remove barriers that people with disabilities face in daily living in Ontario. AODA is legislation thus it has the most power on implementation of the aforementioned documents. These accessibility standards apply to both public and private organizations. This landmark legislation dictates that Ontario will be fully accessible to people with disabilities by 2025. As a result of this new law, the Province created the Standards Development Committee to oversee the creation of accessibility standards and to plan targets for 5-year increments in order to measure progress.

The Ontario Human Rights Code defines disability as:

(a) any degree of physical disability, infirmity, malformation or disfigurement that is caused by bodily injury, birth defect or illness and, without limiting the generality of the foregoing, includes diabetes mellitus, epilepsy, a brain injury, any degree of paralysis, amputation, lack of physical co-ordination, blindness or visual impediment, deafness or hearing impediment, 
muteness or speech impediment, or physical reliance on a guide dog or other animal or on a wheelchair or other remedial appliance or device,

(b) a condition of mental impairment or a developmental disability,

(c) a learning disability, or a dysfunction in one or more of the processes involved in understanding or using symbols or spoken language,

(d) a mental disorder, or

(e) an injury or disability for which benefits were claimed or received under the insurance plan established under the Workplace Safety and Insurance Act, 1997; ("handicap”)

(Human Rights Code)

From above, it is clear that disability comes in many forms and is both visible and invisible. As identified in the Accessibility for Ontarians with Disabilities Act the, five barriers of accessibility are (1) architectural and/or physical - design of spaces (layouts, dimensions, details), (2) information or communication - information that cannot be accessed due to sensory impairments, (3) attitudinal - people lacking understanding or have misconceptions of people with disabilities, (4) technology - when information cannot be accessed with assistive technology, and (5) policy or practice - organizations or systematic barriers that unfairly discriminate or prevent individuals from participating.

The Accessibility for Ontarians with Disabilities Act is an evolution of a previous Act, the Ontarians With Disabilities Act (ODA) from 2001. In the ODA, "the Ontario government and broader public sector, which includes municipalities, public transportation organizations, colleges and universities, hospitals and school boards, [have to] develop annual accessibility plans" (Government of Ontario, 2005, p. 7). AODA expands on these guidelines by creating mandatory accessibility standards across five (5) key areas in Ontario:

1. Accessible Customer Service: public sector organizations must comply by January 1, 2010; private organizations must comply by January 1, 2012. Business practices and training to provide better customer service to people with disabilities.

2. Accessible Information and Communications: design guidelines for print, website, and other forms of communications. 
3. Accessible Built Environment: standards to address access into and inside buildings and outdoor spaces through expanding the Ontario Building Code. Includes attention to door and aisle widths, counter heights, parking, and signage

4. Employment Accessibility: standards for recruitment and retention of people with disabilities for employment

5. Accessible Transportation: addressing aspects of public transportation

(Government of Ontario, 2005)

AODA affects planning in a few ways: (1) how planners engage with communities and respond to their specific needs for accessibility, (2) planning and designing the accessible built environments, and (3) planning and designing accessible transportation options. In summary, AODA has made amendments to the Ontario Building Code (Section 3.8) in 2015 to ensure that the design of public spaces are made to be accessible for the different needs of people with disabilities (refer to Appendix B: Overview of Updated Accessibility Requirements). Also, the new accessibility standards for training staff and government communications will help service providers better serve people with disabilities.

With regards to the planning practice in Toronto, AODA is implemented into practice in a few ways. AODA has created design standards for all government communications and publications. These guidelines set out specific requirements for all forms of government communications including print and online content among other forms of communications. Both public and private organizations are now mandated to train their staff with accessibility standards. These customer service standards are grounded in the notion on promoting inclusivity.

The accessibility standards also affect the built environments in Ontario. With the new accessibility standards, the Ontario Building Code now has regulations pertaining to the size of washrooms, access to entrances and exits, ramps and stairs, elevators, signage, and accessible routes. The standards that affect public transportation are related to communications of information as well as technical specifications of vehicles. Transportation providers are now legally required to communicate non-functioning 
accessibility equipment and vehicles now must include courtesy seating as well as space for mobility aids.

Given that planners work in a communicative role, the forms of communications produced will be required to meet AODA standards. AODA also promotes employment of people with disabilities. When planning with the accessibility community; planners should consult the community with representative staff. This can take form in both hiring people with disabilities as part of the planning and consultation team, but also bringing in sign language interpreters or healthcare support workers to public meetings in order to create a more inclusive environment. Other inclusive communication techniques include providing aids for people who have hearing loss, or by providing more staff to assist people with visual impairments. For public meetings to be made accessible, accessibility features of the space and how planners engage must be considered.

Site planning and the development of public space and buildings will have to consider the accessibility standards. These standards are an excellent step towards advancing accessibility in Ontario as they apply to both public and private organizations. There is, however, little mention in the Act pertaining to person-to-person engagement or other non-traditional forms of engagement. These aspects are only suggested through supplementary documents; where efforts will vary from practitioner to practitioner.

As Paquette and Rogojine (2015) identify, some challenge in planning for accessibility in Ontario include cost and size. Implementing the new accessibility standards into the built environment requires more space because the requirements are generally bigger and wider (Paquette and Rogojine, 2015). Handicap parking spots are wider, doorways and corridors need to be wider in order to accommodate wheelchairs and motorized scooters, and service counters have to be larger and at wheelchair height (Paquette and Rogojine, 2015). Also, installing elements such as tactile indicators, powered door operations, window treatments, and grab bars and benches in washroom can add more costs when building. These costs could be a constraint to 
individuals or developers looking to develop, renovate, or retrofit publically accessible buildings or offices. A suggested area of investigation would be the implications of implementing accessibility standards in heritage properties, and whether or not it is financially prudent and if it strengthens or hinders the heritage elements.

\section{Universal Design and the Aging Population}

The roots of universal design can be traced back to the architect, Ronald L. Mace, in the early 70s' (Center for Universal Design NCSU, 2008). Mace established the term, universal design, in order "to describe the concept of designing all products and the built environment to be aesthetic and usable to the greatest extent possible by everyone, regardless of their age, ability, or status in life" (Center for Universal Design NCSU, 2008, para. 2). Mace's work on pioneering accessible and barrier-free design in architecture directly influenced the inception of the Americans with Disabilities Act (ADA) of 1990 (Center for Universal Design NCSU, 2008). ADA is the American comparable to the Canadian Accessibilities for Ontarians with Disabilities Act. Universally designed spaces, experiences, and/or products make for inclusive uses. Universal design helps all people regardless of age or ability; therefore in designing universally at earlier stages of development processes will create inclusive experiences.

Generally, as people get older, the number of people with disabilities also increases. The World Health Organization (WHO) has published many documents pertaining to the development of age-friendly cities. As the World Health Organization (2007) states, "[p]opulation ageing and urbanization are two global trends that together comprise major forces shaping the $21^{\text {st }}$ century" (p. 1). In the near future, the baby boomer generation will be reaching the senior age group; as a result of an aging population, issues of accessibility will subsequently become more apparently as disability often correlates with aging. The WHO (2007) states, "[t]he world is rapidly ageing: the number of people aged 60 and over as a proportion of the global population will double from $11 \%$ in 2006 to $22 \%$ by $2050 "$ (p. 3 ). 
As people get older, they tend to require supportive, enabling, and accessible environments to compensate for the physical and social changes that are associated with aging (WHO, 2007, p. 4). Creating age-friendly cities will utilize many concepts of universal design, not only in physical landscapes, but in everyday products and experiences as well. Planning for the future needs of residents is the most logical and practical strategy in preparing for the impending demographic shift.

\section{Summary of Literature Review}

This literature review has presented the current state of public participation including its criticisms, using ICT for public engagement activities, an overview of accessibility planning in the context of Toronto, a discussion on the Accessibility for Ontarians with Disabilities Act, and concepts of universal design and the aging population. In engaging with people with disability on planning matters, practitioners must not only understand the needs of the community with disabilities, but they must understand the appropriate avenues for reaching them.

In the following case study, an analysis of strong government policies and commitment in Berlin led to a shift in the development culture of the city, whereby universal design elements are considered early on in the design process. Berlin is a notable example of accessibility as it has previously won the European Union's AccessCity Award in 2013 for its efforts in barrier-free spaces and the inclusion of people with disabilities in decision-making processes. Berlin continues to be a leading example of a major city that considers accessibility as a top priority. 


\section{CASE STUDY: Berlin, Germany}

"No other European country provides as much information for disabled people as Germany" (Neumann and Uhlenkueken, 2001, p.370).

This case study explores the results of strong policies that provide guidance on inclusive and universally designed spaces in Berlin, Germany and how these policies have shifted the culture surrounding accessibility and people with disabilities. The focus of this case study illustrates how Berlin communicates with people with disabilities about accessible spaces, and their stringent policies on building barrier-free spaces.

Berlin is the capital of Germany and is one of the nation's sixteen (16) states. It is the second most populated city in the European Union. Berlin is both a city and a federal state (stadtstaaten or city-state), so it has its own Senate Department for Urban Development and the Environment (Senatsverwaltung für Stadtentwicklung und Umwelt). The way Berlin's planning department is set up is starkly different from Toronto's planning structure where the City is a single-tier municipality that works under the Province of Ontario. Berlin, however, acts as its own state (or province in the Canadian equivalent). In 2015, Berlin had a population of 3.5 million within its borders with a city area of $892 \mathrm{~km}^{2}$ (Statistics Berlin Brandenburg, 2015).

Berlin is "considered to be an international city of culture, politics, media and science" (European Union, 2013, p. 5). What is remarkable about Berlin is its blatant commitment to accessibility and universal design. In 2013, Berlin won the $3^{\text {rd }}$ annual Access-City Award. This prize is given to European cities that go above and beyond in creating accessible environments in all areas of life (European Union, 2013, p.4). The Access-City initiative was created to promote best practices that utilized innovative projects to address accessibility challenges among European cities.

Berlin won this award because of its "strategic and inclusive accessibility policies, which cover all aspects of city life and are firmly embedded in both the political and budgetary frameworks of the city" (European Union, 2013, p. 5). The Access-City 
Awards highlighted two (2) of Berlin's innovative approaches to addressing accessibility in the city: Mobidat - a free online database for barrier-free living, and the Barrier-free City Round Table.

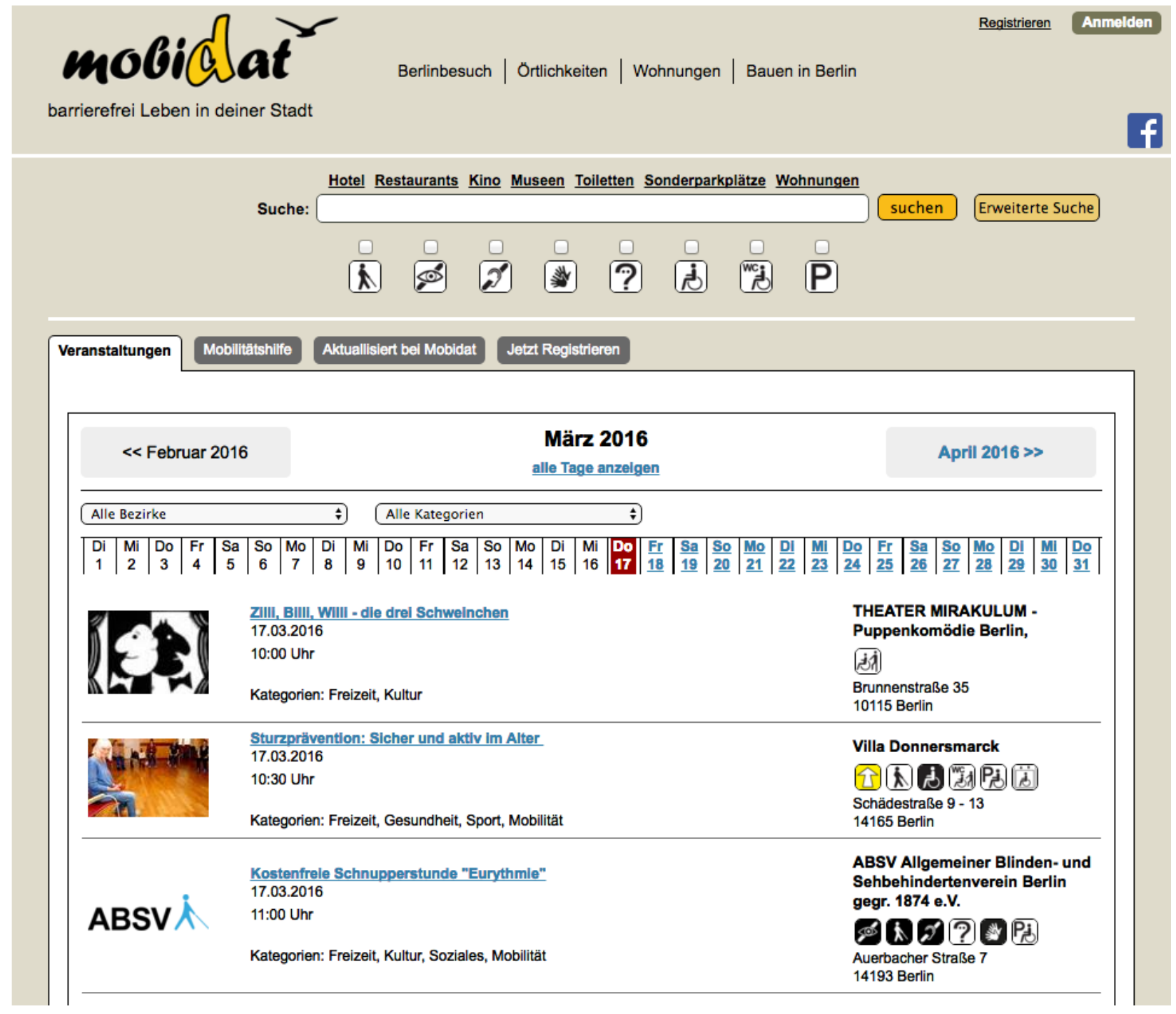

Figure II - Screenshot of Mobidat

The Mobidat project (www.mobidat.net) is an online database that provides users with accessibility information facilities for everyday life and leisure. This project encourages people with disabilities to explore Berlin independently through the provision accessibility information on facilities. The accessibility information is generated from Berlin's barrier-free Deutsches Institut für Normung (DIN) standards, which is 
Berlin's version of the Ontario Building Code. The DIN standards outline specifications to how buildings and spaces are developed. Reporting the state of accessibility standard and features is mandatory in Germany. Mobidat utilizes 20 years of documenting accessibility information in Berlin to show users which facilities are accessible. The project also features a calendar of accessible events and shows users how to travel to the events and facilities.

Mobidat was created through collaboration between the Senate Department for Urban Development and the Environment and a non-profit IT company, Albatros $\mathrm{gGmbH}$. The project is funded by the Senate Department, and has employed over 40 employees with disabilities between 2009 and 2011. Figure II is a screenshot of the Mobidat project.

The second project the Access-City Awards highlighted was the Round Table for a 'Barrier-free City' stewarded by the Senate Department for Urban Development and the Environment. This Round Table was created to discuss topics around accessibility and creating barrier-free spaces and experiences in Berlin. The Round Table consists of a wide range of stakeholders from various fields. Government officials, experts in the field, business owners, community organizations, tourism industry, accommodations, and transportation services all have representation at the Barrier-free City Round Table. Key decision makers such as representatives from other Senate departments, the Berlin Commissioner for People with Disabilities, and the State Advisory Council for People with Disabilities are also members of the table. The Round Table was created with the purpose to agree on priorities of Berlin moving forward on issues surrounding accessibility. The initiative is "chaired by the Permanent Secretary for Building and Housing. This means that it has high-level decision-making powers" (European Union, 2013, p.8).

The Round Table for a "Barrier-free City" meets four (4) times a year, and was created to ensure the implementation of the UN Convention on the Rights of Persons with Disabilities, as well as the European Strategy Disability Strategy; which created 
policies based on a "design for all" principle (European Union, 2013, p. 8). In 2013, Berlin set the priority of developing a strategy to address their growing demand for accessible tourism. A direct result of the Round Table discussions was the creation of an accessible tourism database: http://www.visitberlin.de/en/plan/city-info/accessible. This database provides visitors with disabilities information on accommodations, travel, programming, and activities and events. This website is offered in different languages, whereas the aforementioned Mobidat project was only offered in German. The differences between the two projects are that the tourism database is targeted for visitors, whereas Mobidat is geared towards Berliners.

The Senate Department for Urban Development and the Environment is an innovative branch of the German government that deals with housing, building, planning, traffic, the environment, and heritage in Berlin. The Senate building, at Am Köllnischen Park 3, in the borough of Mitte, houses a permanent urban planning exhibition titled: City Models of Berlin. The exhibition features full-scale 3D models of Berlin past and present. The main exhibit is a large interactive city model where users can project information onto the 3D models to identify buildings by the criteria they have chosen. The exhibition also houses historical models of both East and West Berlin before unification.

The most interesting exhibit, however, is the Talking City Model (Sprechendes Tastmodell). This installation is a full city model of Berlin city centre at a scale of 1:2000 that is meant to be touched. These models were originally built for people with visual impairments, but because of the principles of universal design, all are able to enjoy it. The models created a tactile experience of the features of the city so that the audience can feel the different textures of the buildings and the city. The issue, however, is that it is unclear if the concept of the scale of a building comes across with these models.

Figure III and Figure IV are photos of the tactile models in the exhibition. 


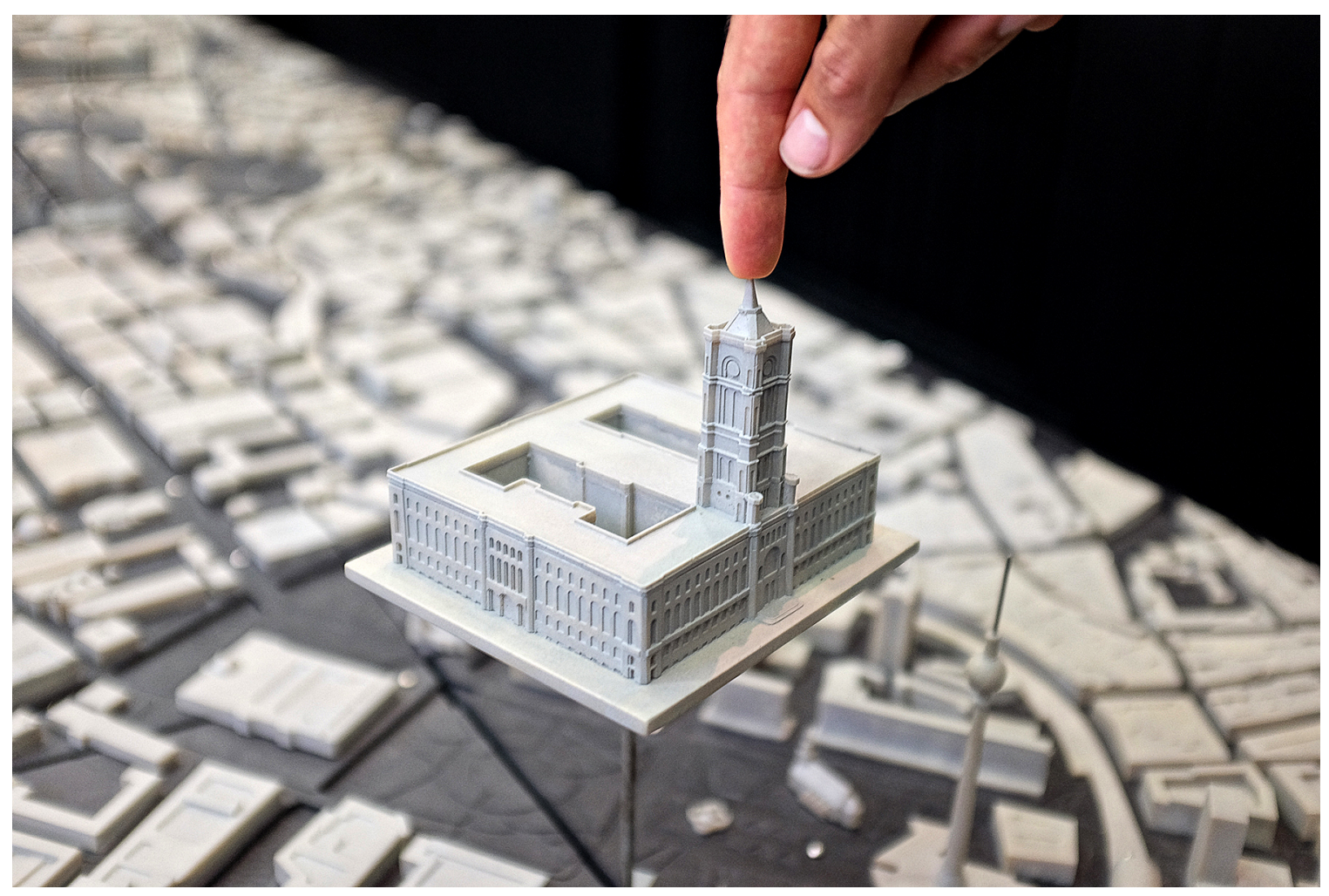

Figure III - Detail of Tactile Features of the Talking City Model

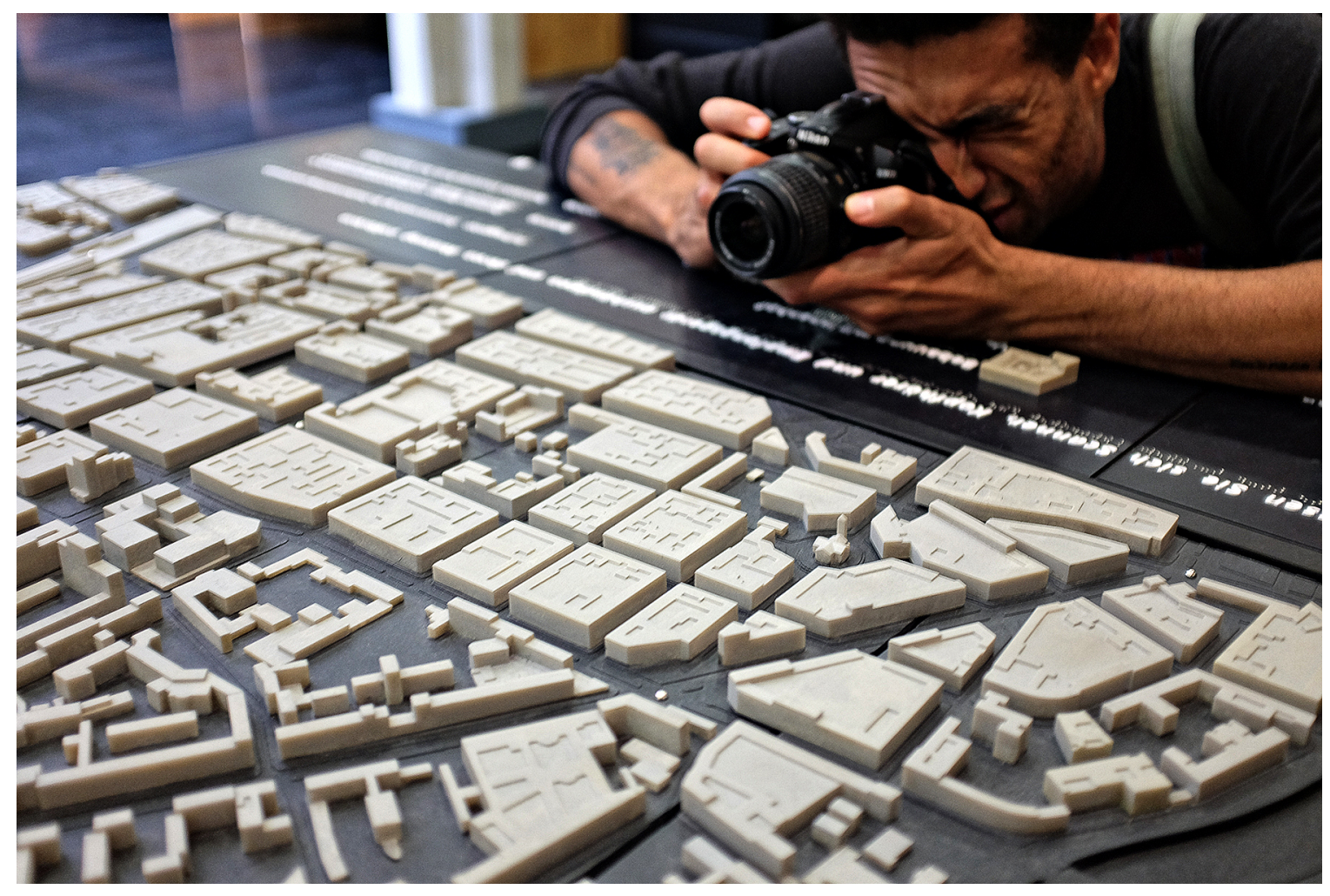

Figure IV - The Talking City Model 
There is also an audio guide that accompanies the exhibit. The Talking City Model was created through a collaborative effort between the Technical University of Berlin, the Senate department, and a team of people with disabilities (Senate Department for Urban Development and the Environment, n.d.). The models provide a multi-sensory experience for exploring various buildings and urban features of Berlin.

The City Models of Berlin exhibition is a tool for awareness and education. The building itself is fully accessible by people with disabilities. There is also a conference area in the exhibition where planners host info sessions and community meetings. The models themselves are educational, in that they provide information on urban planning in Berlin to visitors. People with disabilities also staff the exhibition space.

Berlin is an example of strong accessibility policies because of the legal framework that ensures barrier-free access. There are a sizable amount of legal documents that pertain to barrier-free planning and construction in Berlin (refer to Appendix C: Overview of the Legal Framework in Berlin). Broadly speaking, planning for accessibility is largely driven by the European Disability Strategy 2010-2020. This strategy outlines 8 guiding principles: accessibility, participation, equality, employment, education and training, social protection, health, and external action (European Commission, 2010).

In December 2015, the European Union launched a new round of public consultation for their mid-term review of the European Disability Strategy. In these public consultation events, the EU will be asking participants on their opinion on what has been achieved so far based on the principles, their views on the challenges faced by people with disabilities, and how the EU should address said challenges (European Commission, 2015).

The European Disability Strategy was created in order to apply the principles from UN Convention on the Rights of Persons with Disabilities. The UN convention was created in order to "promote, protect and ensure the full and equal enjoyment of all human rights and fundamental freedoms by all persons with disabilities, and to promote 
respect for their inherent dignity ... [and to] change perception of disabilities" (United Nations, n.d.). This convention steamed the concepts discussed from Declaration of Barcelona: The City and The People, 1995, which declared that it was the responsibility of the community and social organizations to promote favourable conditions for all people (Neumann and Uhlenkueken, 2001).

The main document that guides accessible development in Berlin is the Senate department's Barrier-free Planning and Construction in Berlin: Principles and Examples. This document was 'designed to heighten planners' and decision-makers' awareness and understanding on the one hand and to offer concrete advice in addition to existing rules, regulations, and building standards on the other." (Senate Department for Urban Development and the Environment, 2007, p.4). Barrier-free Planning and Construction series highlights design specifications for public space and buildings in Berlin, along with general best practice design guidelines for universal access and design. This document was an evolution from a 1992 document Guidelines For Making Berlin A More Disabled More Disabled-Friendly City from 1992, which addressed public transit, design of public streets and open space, and design of public buildings.

From this case study, it is evident that Berlin has strong government support in policies that promote accessibility and universal design. The barrier-free policies were an evolution from ideas that can be traced back to the 1990's with the Declaration of Barcelona: The City and The People, which evolved into the UN Convention on the Rights of Persons with Disabilities, and Berlin's Guidelines For Making Berlin Guidelines For Making Berlin A More Disabled More Disabled-Friendly City. As a result of this progressive of social policy, the European Disability Strategy was created in order to provide direction on design and social implications.

Berlin's state planning structure has the capacity to sustain funding support for state-led barrier-free planning and engagement. They monitor their progress at their Barrier-free City Round Table sessions, where they also map out long-term visions for how a barrier-free Berlin will continue to evolve. Berlin engages the people with 
disabilities community by having representatives from public and advocacy organizations at the Round Table discuss, while publishing many barrier-free documents in order to continue its awareness campaign. These strong policies and practices have affected Berlin's culture of development, in that designing for all at the inception of development is beneficial as universal design is accessible to all.

In the long-term, Berlin's barrier-free construction policies are implementing the principles of the European Disability Strategy. These policies are aimed at removing more physical and social barriers to accessing the city by all people. Going forward, suggested areas of future research on barrier-free construction should consider exploring how the Berliners receive and perceive accessibility. Are the barrier-free design concepts working for affected populations? Do people notice the changes in the physical environment? Are people with disabilities still excluded from various areas of participation or urban processes? 


\section{KEY FINDINGS}

Based on the case study of Berlin, it is apparent that strong government policies can influence a change in the culture of development and public perception of disabilities. By embedding concepts of accessibility into their policies, Berlin was able to spread awareness of accessibility issues quickly both online and using their exhibition space. Berlin has shifted its own culture of development by focusing on universal design in order to promote inclusivity in built form. In doing so, Berliners are being exposed to the benefits of universal design that they are not just for people with disabilities, but also for everyone. Berlin's planning department also invites participation by people with disabilities to their Round Table on the Barrier-free City and they educate the public with their barrier-free design publications and city models exhibition.

Based on the review earlier of literature surrounding public engagement and using information and communications technology for engagement, a few key findings surface. Planners need to use mixed methods to engage audiences with accessibility needs, good public engagement must be a mixture of high and low tech exercises, just because engagement is online does not mean that it is accessible, and strong government policies can shift civic development culture as well as public perception on accessibility issues. As Dave Biggs (2016) notes that each vulnerable and/or disadvantaged group present unique engagement challenges that can be addressed when practitioners use a variety of engagement techniques. When engaging with the accessibility community, online engagement may not be ideal. Webpage design guidelines can only go so far in creating accessible content, but planners should offer supplementary options for accessing the information; for instance, providing a personto-person or call-in service to individuals who would rather interact with another person or listen to audible information in order to better understand the engagement activity.

From the research presented in this paper, it is apparently that using a combination of high and low tech tools are the best means of meaning engagement with the public. 


\section{APPLICATION TO TORONTO}

The Government of Ontario (2015) states, "[a]ccording to the Royal Bank of Canada, people with disabilities have an estimated spending power of about $\$ 25$ billion annually across Canada ... [and that] [i]mproving accessibility can create up to $\$ 9.6$ billion in new retail spending and $\$ 1.6$ billion in new tourism spending in Ontario over five years". Creating an accessible Ontario houses a wide array of benefits that stretch beyond human health and improved quality of life, but also has economic implications as well. As Salah and Chung (2013) state, "Ontario is a forerunner in this global innovative space [on accessibility and universal design" (p. 15). With the implementation of AODA, Ontario became the first jurisdiction to have enforceable accessibility policies and standards that apply to both public and private sector industries.

The city of Toronto is in an advantageous spot to take a deep dive into exploring the possibilities of accessibility and technology because of the current creative state of the city. Toronto has been named Canada's high tech hub because $30 \%$ of Canada's ICT industry is based in the Toronto region (City of Toronto, 2011). The city is known for its startup communities and entrepreneurial spirit.

The Ministry of Research and Innovation (MRI) creates programs to help entrepreneurs start businesses and accelerate growth. One of the programs that came out of MRI was the Ontario Network of Entrepreneurs (ONE). This program is a collaborative network of organizations designed to help startups and technology-based businesses. ONE established fourteen (14) regional innovations centres, and the MaRS Discovery District is Toronto's innovation centre. These innovation centres provide support through the provision of office space, educational workshops, mentoring, market intelligence, and much more.

The strong startup community is just one part to what Ontario calls the innovation ecosystem, which consists of "startups, universities, research institutes and talent" (Salah and Chung, 2013, p.18). As illustrated in Berlin, having the government spearhead the efforts in promoting barrier-free city building was crucial in changing the 
culture of development. Berlins planning structure, however, is very different from Toronto's and has a lot more capacity to do the things they want to do. Therefore it is recommended that governments in Ontario leverage collaborations with the innovation ecosystem in Toronto.

Toronto has a sizable amount of innovators that are currently working on accessibility and universal design in information and communications technology. Ryerson University's Inclusive Media and Design Centre "creates and evaluates inclusive media technology, focusing on solutions for individuals who are blind or have low vision, or who are deaf or are hard of hearing" (Salah and Chung, 2013, p. 32). This centre makes communications content more accessible and has developed EnACT (Emotive and Affective Captioning Tool), which is software that animated captions in order to convey emotion and intensity of script. Interestingly, Ryerson University is the only planning school in Canada in a faculty with a School of Disability Studies. This creates an opportunity to develop innovative ideas on engaging people with disabilities on planning matters through knowledge sharing and collaboration.

At OCADU, the Inclusive Design Research Centre is a research and development lab that designed information technology to be used people very varying abilities. The University of Toronto's Intelligent Assistive Technology and Systems Lab under the Department of Occupational Science and Occupational Therapy are exploring "the intersection of artificial intelligence, sensors and assistive technology" (Salah and Chung, 2013, p. 26).

Toronto's universities recognize the growing field of accessibility and so do the entrepreneurs of the city as well. Small tech firms like Jibestream, GestureTek, and Komodo Openlabs are all working on creating assistive technologies in order to enable people with disabilities to participate in every day tasks and rehabilitation. The Toronto Rehabilitation Institute created the iDAPT Centre for Rehabilitation Research - a research lab that explores the topics of artificial intelligence, cognition, and mobility. The research centre has also created many startups from their own labs and experiments. 
From the research, little is extensively explored around the topic of public engagement with people with disabilities in the planning process. The frameworks that gently touch this topic are mentioned in the AODA standards, and supplementary documents that pertain to executing accessible public engagement activities. There are, however, many other industries that are investing heavily into creating assistive technology for people with disabilities and doing research on the experiences of having disabilities.

\section{Recommendations}

Going forward, for Toronto to explore deeper into engaging with people with disabilities, the city and its organizations can utilize the following strategies to accelerate the dialogue on accessibility in the city. As mentioned earlier in this document, AODA affects planning in a few ways: (1) how planners engage with communities and respond to their specific needs for accessibility, (2) planning and designing the accessible built environment, and (3) planning and designing accessible transportation options. Planners work in a communicative role, they must present accurate information and engage with a wide breadth of audiences. AODA has set out regulations on how publications and communications look, but there is a gap in the way we engage with people with disabilities. Outcomes of engagement activities can influence the physical form. AODA has created accessibility guidelines for buildings and public spaces, however, when combined with the right engagement with the right audiences, the design of these spaces can potentially be even better.

By engaging with the affected population, planners will be better able to address the needs of that community. With the case study of Berlin, we've learned that people with disabilities have the means of accessing a database of accessible spaces in the city, and that they have representation in planning matters with their respective organizations. Berlin has also made it a priority to change the culture of development by focusing on universal design from the inception of the design phase. Their city model 
exhibition acts as a way to bring awareness to their planning efforts and educates the public on planning matters.

In the Government of Ontario, there is an accessibility office titled the Accessibility Directorate of Ontario. This unit was established under the Ontarians with Disabilities Act 2001 with a mandate to implement what the act entails, which is the creation of accessibility standards and awareness tools for accessibility. How accessibility planning actually pans out on the ground, however, is up to the municipality and/or the planning practitioners.

The following section will present ideas that can be added on top of the accessibility standards outlined by AODA in order to promote the cultural shift on accessibility matters as the Province had originally intended.

\section{Develop an accessibility certification program}

The Government of Ontario has expressed interest in developing an Accessibility Certification Program that would encourage businesses to improve accessibility. This certification program will be similar to the LEED designation - a voluntary certification program that promotes excelling in green infrastructure in buildings (Government of Ontario, 2015, p. 13). A certification program could encourage businesses to go above and beyond the AODA building and service standards imposed by the Act, and the incentive would be the recognition of good service.

In creating an accessibility certification program of sorts, planners would be better able to identify or create new spaces that are beyond the mandatory minimum standard for accessibility. A certification program can also suggest how to engage with people disabilities, whether that is using online platforms or hosting a suite of face-toface events with community members.

As a component of this certification program, the organizing body should also recognize cases of outstanding examples in the field, similar to what the European 
Union is doing with their Access-City Awards. Not only will these allow cities or businesses to gain exposure on good work, but also the exposure will act as a form of sharing best practices in order to inspire other practitioners.

In June 2015, Deloitte, an auditing and consultation firm, has begun work on developing a voluntary accessibility business certification process for the Government of Ontario called Certified for Access (Certified for Access, 2016). They are currently in the consultation process of development, but they have determined that the certification program will utilize both in-person and online consultations in order to determine the themes and priorities of the certification program.

\section{Creative public awareness campaigns}

In October 2015, Ryerson University's Policy Innovation Platform hosted Hackcessibility, a policy hack-a-thon that challenged participants on asking the question, "how can we accelerate the dialogue on accessibility with the goal of helping to shift attitudes and change behaviours? Refer to Figure $V$ for a picture from the Hackcessibility event. Just like the Accessibility Innovation Showcase discussed at the beginning of this paper, events like these invite parties into a community they may not have thought existed. Hack-a-thons bring together like-minded individuals from diverse disciplinary and professional backgrounds to generate innovative ideas. 


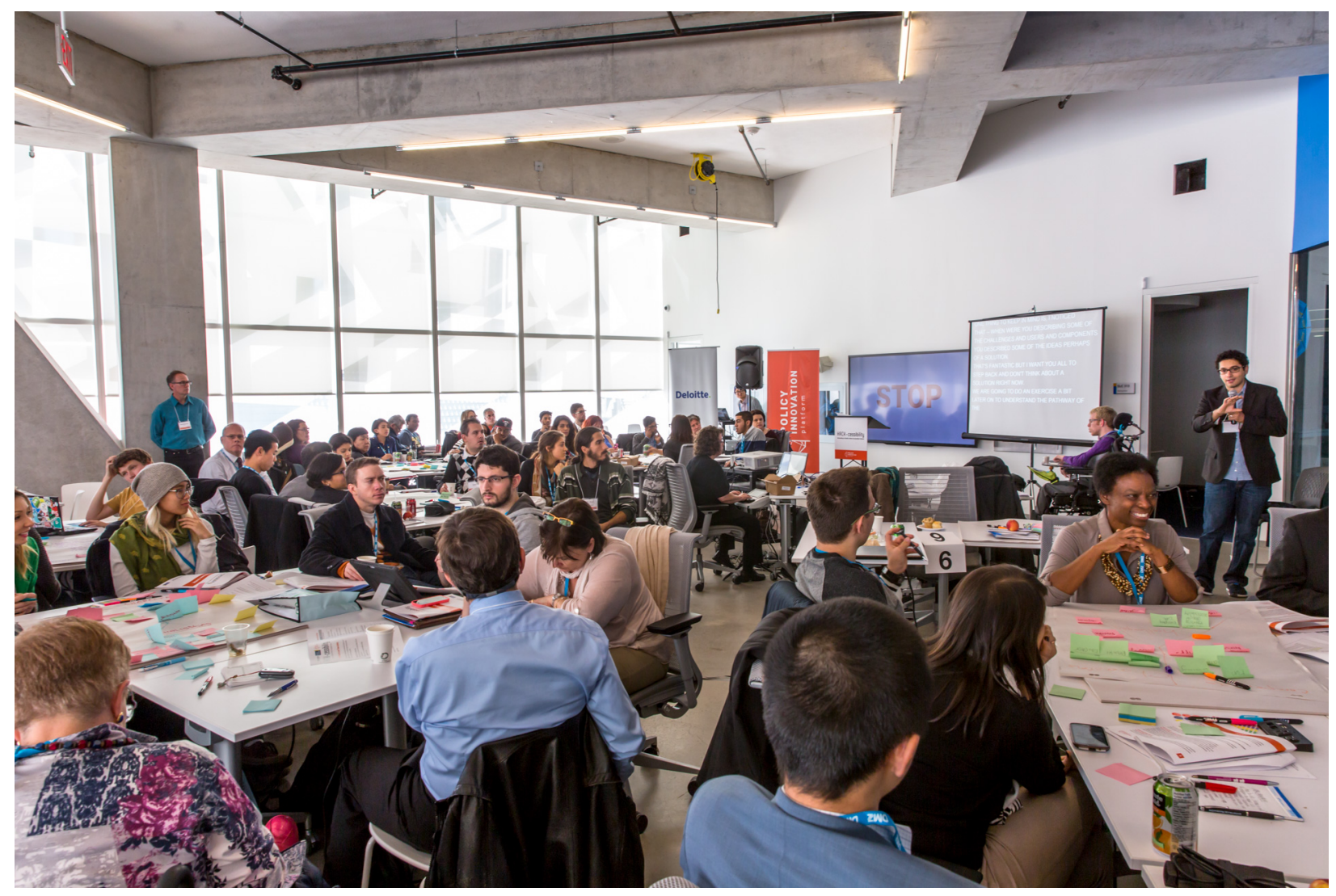

Figure V - Photograph from the Hack-cessibility event. Photo by Brookfield Institute

Public awareness campaigns are where creative collaborations can really generate a strong impact. With Toronto's large creative industries, and massive pool of talent, cross-sectorial initiative that utilize interdisciplinary teams generating multimedia experiences can really drive the message on raising awareness on accessibility. Advocates for accessibility can also better utilize social media and online avenues for more effective engagement in the dialogue around accessibility. Fischer writes on the role of new media takes on social participation

"The major role for new media and new technologies from a culture-of-participation perspective is not to deliver predigested information and non-changeable artifacts and tools to individuals, but rather to provide the opportunity and resources for engaging them in authentic activities, for participating in social debates and discussions, for creating shared understanding among diverse stakeholders, and for framing and solving personally meaningful problems"

(Fischer, 2011, p. 53). 
In sum, Fischer is saying that social networks drive social innovation. The network within Toronto's innovative hubs has the potential to do really great things for the urban experience of all people.

\section{Create an urban planning museum for awareness and education}

With Toronto's many cultural institutions spread throughout the city, what Toronto is really missing is its own urban planning museum, or museum of the city. Museums have what Lord and Blankenberg (2015) call "soft power" - which is not military, economic, or politic might, but influence (p. 4). As Lord and Blankenberg (2015) states, "[m] useums empower people when they are patrons for artists and thinkers; when they amplify civic discourse, accelerate cultural change, and contribute to cultural intelligence among the great diversity of city dwellers, visitors, policy-makers and leaders" (p. 19). Museums are important for place making in cities, for the identity of the cities, and are also for accelerating cultural change when exhibiting topics on complex social change.

As depicted in the case study of Berlin and the permanent City Models of Berlin exhibition, such spaces can provide educational opportunities for both residents and visitors. The city of Vancouver, Canada, also has a city museum: Museum of Vancouver. In Vancouver, this museum discusses urban issues and persuades its visitors to envision the future of the city.

In creating a city museum, planners can showcase new ideas in the accessibility community by designing inclusive spaces, or showcasing the latest assistive devices and what not. Museums offer spaces for dialogue. The manifestation of cultural context in museums itself house a strong statement that the exhibits are exhibited to convey some sort of cultural meaning. In showcasing accessibility, the public will understand its importance. 


\section{CONCLUSION AND AREAS FOR FURTHER RESEARCH}

To reiterate, "[d]isability, in relation to the physical or spatial environment and products, is often defined as resulting from the interaction between individual skills (or abilities) and the conditions of the surroundings in which such skills (or abilities) are manifested" (Neumann and Uhlenkueken, 2001, p. 367). As mentioned earlier in this paper, people are not disabled; it is the environment that is disabling. We as city builders must ensure that both spaces and places are inclusive to all through universal design principles. Universal design creates equitable use and access to the city.

In regards to engaging the accessibility community with technology, that field is still largely unexplored with the exception of stringent design guidelines that detail how communications should look in order to maximize legibility. Suggested areas of for further research would be to ask the accessibility community what the barriers to public participation are. Are they having trouble accessing the information on participation? Are they having trouble accessing the events and activities? Or is it both? What are the outcomes of engagement efforts with people with disabilities?

When guidelines or standards are imposed, it is often seen as restrictive. Another area for further research that would be interesting to conduct is asking the question whether or not the Accessibility for Ontarians with Disabilities Act is dumbing down design; in spatial environments, online engagement, and communications.

There is a growing field of research that explores how people with varying degrees of physical and mental health perceive spaces. Tactile surfaces and audible features can assist people with vision impairments navigate city spaces and there are design guidelines that optimize the legibility of spaces for people with dementia. The implication for planners in regards to engaging with people with disabilities is questioning what the most appropriate methods of reaching the right people. Throughout this paper, we've discussed that a mixture of both conventional and nontraditional methods of engagement is best for engaging with the underrepresented populations as they allow for broader audiences to participate. 
Tim Ross (2013) presents an interesting perspective on the Accessibility for Ontarians with Disabilities Act. He argues that AODA can change the social perception on issues of accessibility but critiques the language and discourse surrounding AODArelated texts (Ross, 2013). Ross (2013) suggests that the Act should not emphasize the biomedical conceptualizations of disability because it does not support the social goal of AODA, which is to remove social barriers of people with disabilities (p. 128). Ross is critiquing the semantics of the people-first language and the usage of the word "disability". He claims that the language and discourse itself is reinforcing social barriers. In associating the efforts of AODA with the word "disability", there is still the notion or undertone that people are limited in or lacking ability rather than removing the dichotomy of "us" and "them" (Ross, 2013, p. 135). This unintended consequence is separating the audiences, and is perpetuating the identity of disability when AODA is still associated with the word "disability". Since the purpose of AODA is to advance accessibility in Ontario and educate public on accessibility issues and since accessibility benefits all people, Ross (2013) suggests that the Accessibility for Ontarians with Disabilities Act should reconsider naming itself towards the something closer to universal accessibility (Ross, 2013, p. 139)

As public interest is the first responsibility in the Ontario Professional Planners Institute's Professional Code of Practice, the planner's responsibility is first to the public. In understanding how to engage with people with disabilities and their needs, planners will become more culturally sensitive and aware of the designs and interventions they propose. Ultimately, the objective is to push the planning practice to engage better with people with disabilities in order to create better, universally designed spaces. As planners engage with vulnerable and underrepresented populations, they will be able to create better spaces as they utilize local knowledge, notwithstanding the potential to build partnerships and build awareness along the way - and is that not what city building is about all along; building connections?

As Kendrick Lamar (2013) raps, "they say conversation rule a nation, I can tell; but I could never right my wrongs 'less I write 'em down for real". From systems-level to 
social change, the communication between different communities on their relationships is how change starts. And the absolute strongest indicator of change is written in policy. Ontario has become a trailblazer in generating attention around accessibility issues with its landmark legislation, the Accessibilities for Ontarians with Disabilities Act. With a collaborative effort that involves government, creative industries, and people with disabilities, Ontario will become fully accessible. 


\section{APPENDICES}

\section{Appendix A}

\section{Facts from Path to 2025}

Ontario is the first jurisdiction in the world to require staff to be trained on accessibility.

Ninety per cent of Canadians believe that people with disabilities are not fully included in society.

Penalties for non-compliance range from $\$ 200$ to $\$ 2,000$ for individuals and unincorporated organizations; and from $\$ 500$ to $\$ 15,000$ for corporations.

The Ontario Public Service (OPS) has been named one of Canada's Best Diversity Employers for eight consecutive years (2008-2015).

Improving accessibility can create up to $\$ 9.6$ billion in new retail spending and $\$ 1.6$ billion in new tourism spending in Ontario over five years.

By 2035, 40 per cent of our consumer base will be people with disabilities.

More than 40 per cent of Ontarians with disabilities have some type of postsecondary credential.

Seventy per cent of small businesses say they have never hired a person with a disability.

Seventy-five per cent of small business employers who have employees with a disability report that they meet or exceed their expectations.

Source: Government of Ontario. (2015). The Path to 2025: Ontario's Accessibility Action Plan. Retrieved from the Government of Ontario's website:

https://www.ontario.ca/page/path-2025-ontarios-accessibility-action-plan 


\section{Appendix B}

\section{Overview of Updated Accessibility Requirements}

On December 27, 2013, Ontario Regulation 368/13 was filed to amend the new 2012 Building Code, O.Reg. 332/12.

The effective date of the amendment is January 1, 2015.

The amended requirements will substantially enhance accessibility in newly constructed buildings and existing buildings that are to be extensively renovated. They maintain Ontario's leadership role in requirements for barrier-free design.

In 2005, the government committed to the development of five accessibility standards under the Accessibility for Ontarians with Disabilities Act. These amendments to the Building Code work together with the Design of Public Spaces standard, introduced in 2012, to finalize the government's commitment to an accessibility standard for the built environment.

Five accessibility standards are already in regulation under the Accessibility for Ontarians with Disabilities Act: Customer Service, Information and Communications, Employment, Transportation, and Design of Public Spaces. For more information on Accessibility Standards, please visit www.ontario.ca/AccessOn.

Requirements apply to most new construction and extensive renovations. Existing buildings, where no work is planned, are not affected by these new requirements. Houses, including semi-detached houses, townhouses, and duplexes, are not affected by most accessibility requirements, with the exception of smoke alarm requirements.

\section{Barrier-Free Path of Travel}

Ontario's Building Code requires a barrier-free path of travel throughout most occupancies and building types. The Building Code also sets a number of requirements related to common access and circulation throughout buildings. These include requirements related to building entrances, minimum doorway and corridor widths, ramp dimensions, passing and rest spaces, and turning spaces.

New amendments update these requirements in a number of ways. Key changes include:

- Requirements for power door operators to be provided at the entrance door and entry vestibule of most buildings

- Requirements for power door operators at the door to amenity rooms - such as party rooms or movie rooms for building residents - in multi-unit residential buildings 
- Updated door width, hallway passing space and curb ramp dimensions

- New requirements for tactile walking surface indicators at the top of stairs and at platform edges, which help alert pedestrians with low vision that they are entering an area of potential hazard.

\section{Access to All Storeys Within a Building - Elevators}

Providing elevator access to all floors in a building allows visitors and occupants to travel throughout the building with ease, regardless of ability. A key change introduced with these amendments will make that a reality for many buildings across the province. Most new buildings will be required to provide barrier-free access between all floors, including assembly buildings (such as theatres, community centres, and places of worship), care buildings (such as long-term care homes), and commercial/retail buildings (such as supermarkets and shops). The same requirement will apply to residential and office buildings over three storeys in height or over 600 square metres in building area. This approach provides flexibility for small infill buildings, consistent with Ontario's goal of urban intensification and mainstreet redevelopment.

Some exemptions will apply. For example, some small group homes with under 10 occupants are already exempt from elevator requirements. This exemption will continue. In addition, restaurants will not be required to provide access to upper floors if the same amenities are provided on all floors - for example, if a bar or restaurant has a second or third storey with additional seating, access would not be required.

Finally, floors without elevator access have previously been exempt from full accessibility requirements. With these new amendments, those floors will have to be designed with basic accessibility features. Examples of these basic accessibility features are lever door handles, barrier-free doorways and ambulatory washroom stalls equipped with parallel grab bars and suitable for individuals with limited balance or who use assistive devices such as a cane or walker.

\section{Visitable Suites in Apartment Buildings}

New amendments increase from 10 per cent to 15 per cent the minimum number of suites within a multi-unit residential building that must be designed with basic accessibility features. These accessible features have also been updated, and will provide a barrier-free path of travel and doorway into a bedroom, full bathroom, kitchen and living room. These suites must be distributed throughout the building and must represent the types and sizes of suites otherwise available in the building.

\section{Visual Fire Safety Devices}

Approximately 10 per cent of Canadians report having a significant hearing problem. Visual fire alarms and smoke alarms equipped with a visual component are an important part of enhancing the safety and security of all Ontarians. New amendments expand the range of areas where visual fire alarms will be required, including in public corridors of all residential buildings, in all multi-unit residential suites, and in all barrier-free and universal washrooms. 
Smoke alarms are required by the Building Code to be provided on every floor and in every sleeping room of residential buildings, including all houses. As of January 1, 2015, all smoke alarms will be required to include a visual component conforming to National Fire Protection Association standards.

\section{Washrooms}

The Building Code requires barrier-free washrooms to be provided in public areas of most buildings. These washrooms must be situated on a barrier-free path of travel and are subject to a number of requirements addressing turning space, doorway widths, grab bars, counter heights and signage, among others. The Building Code also sets requirements related to barrier-free showers and bathtubs.

New amendments update these requirements in a number of ways. Key changes include:

- $\quad$ Requirements for power door operators at the entrance door to all barrier-free and universal washrooms

- Amended mounting height and location requirements for washroom accessories such as towel dispensers and hand dryers

- New fold-down grab bar design options to allow for transfer space on both sides of the water closet

- $\quad$ Requiring an L-shaped grab bar in all cases and removing the option to provide a diagonal grab bar

- Increased minimum clear floor area in barrier-free washroom stalls required to allow for turning space

At least one universal toilet room would also be required in all buildings, and, for multistorey buildings, at least one for every three floors. Space for an adult change table will have to be provided in all universal toilet rooms except in buildings under 300 square metres in building area.

\section{Access to Pools and Spas}

Pools and spas provide important recreational and exercise opportunities for many Ontarians of all ages and abilities. New amendments require barrier-free access to and around all public pools and some public spas, via ramps, transfer walls or pool lifts.

\section{Accessible and Adaptable Seating Spaces}

New amendments update requirements for accessible seating spaces provided in public assembly buildings, enabling people with disabilities to equitably and independently access educational and worship opportunities. In addition, new requirements address adaptable seating spaces suitable for a side transfer from a wheelchair, as well as storage spaces for wheelchairs and other mobility assistive devices. Accessible and adaptable seating spaces will be required to be distributed throughout the viewing area. Requirements for adjacent companion seating for accessible seating spaces will enable people of all abilities to enjoy these opportunities together in an integrated fashion. 


\section{Renovations}

Renovation projects provide opportunities for enhanced accessibility in existing buildings. Currently, however, accessibility requirements in Ontario's Building Code only apply to extensive renovations undertaken in suites over 300 square metres in building area and located on an accessible floor level - i.e., on the main floor of a building or on a floor with elevator access. New amendments set out basic accessibility features that must be included in extensive renovations undertaken in smaller suites or suites located on a floor level that is not fully accessible. Examples of these basic accessibility features are lever door handles, barrier-free doorways and ambulatory washroom stalls equipped with parallel grab bars and suitable for individuals with limited balance or who use assistive devices such as a cane or walker.

Extensive renovations in larger suites and on an accessible floor level will continue to be subject to all accessibility requirements set out in the Building Code.

\section{About Ontario's Building Code}

Ontario's Building Code establishes the minimum standards for the construction of the buildings in which all Ontarians live, work and play. By providing clear and consistent standards, Ontario's Building Code helps keep Ontarians safe, facilitates the work of builders and developers, and supports key government priorities. One of those key priorities is an accessible Ontario.

Barrier-free design requirements have been part of Ontario's Building Code since 1975. As part of achieving Ontario's goal of an accessible Ontario by 2025 , Ontario is working to create a Building Code that demonstrates leadership in barrier-free design and is responsive to the needs and concerns of all its stakeholders.

\section{About the Accessibility for Ontarians with Disabilities Act}

The Accessibility for Ontarians with Disabilities Act, 2005 (AODA) became law on June 13, 2005. The purpose of the AODA is to benefit all Ontarians by developing, implementing and enforcing accessibility standards. The goal is to achieve accessibility for Ontarians with disabilities with respect to goods, services, facilities, accommodation, employment, buildings, structures and premises by January 1, 2025.

Source: Government of Ontario - Ministry of Municipal Affairs and Housing Website, http://www.mah.gov.on.ca/Page10547.aspx 


\section{Appendix C : Overview of the Legal Framework in Berlin}

General Principles

3.5. Overview of laws and regulations

\section{OVERVIEW OF THE LEGAL FRAMEWORK IN BERLIN}

\begin{tabular}{|c|c|c|}
\hline Social laws & Building regulations & Other codes \\
\hline $\begin{array}{l}\text { BASIC LAW } \\
\text { Article } 3 \text { para } 3 \\
1994 \\
\text { Ban on discriminating against } \\
\text { people with disabilities } \\
\text { http://bundesrecht.juris.de/gg/ } \\
\text { art_3.html } \\
\text { GUIDELINES FOR MAKING } \\
\text { BERLIN A MORE DISABLED- } \\
\text { FRIENDLY CITY } \\
1992 \text { and continuation } \\
\text { in } 1996 \\
\text { LAW ON ARTICLE 11 OF } \\
\text { THE BERLIN CONSTITUTION } \\
\text { EQUAL RIGHTS ACT (LGBG) } \\
\text { 1999 } \\
\text { (Provision of equal living } \\
\text { COnditions for people with } \\
\text { and without disabilities) } \\
\text { 1999, GVBI. p. } 178 \text { and } \\
\text { amendments } \\
\text { EQUAL OPPORTUNITY FOR } \\
\text { PEOPLE WITH DISABILITIES } \\
\text { ACT (BGG) 2002 } \\
\text { Ban on discriminating against } \\
\text { people with disabilities } \\
\text { 2002, BGBII.Ip. 1467 } \\
\text { http://bundesrecht.juris.de/bgg/ }\end{array}$ & $\begin{array}{l}\text { BUILDING REGULATIONS } \\
\text { FOR BERLIN } \\
\text { From 01.02.2006 } \\
\text { 2005, GVBI. p. } 495 \\
\text { 2006, GVBI. p. } 819 \\
\text { SECOND ACT ON THE } \\
\text { SIMPLIFICATION OF LAWS } \\
\text { AND THE REDUCTION } \\
\text { OF BUREAUCRACY } \\
\text { Dated 14.12.2005 } \\
\text { EVACUATION REGULATIONS } \\
\text { (EvakVO) } \\
\text { Dated 15.06.2000 } \\
\text { 2000, GVBI. p. } 361 \\
\text { REGULATIONS ON THE } \\
\text { OPERATION OF SPECIAL } \\
\text { BUILDINGS (SoBeVo) } \\
\text { Dated 18.04.2005 } \\
\text { GVBI. 2005 p. } 260\end{array}$ & 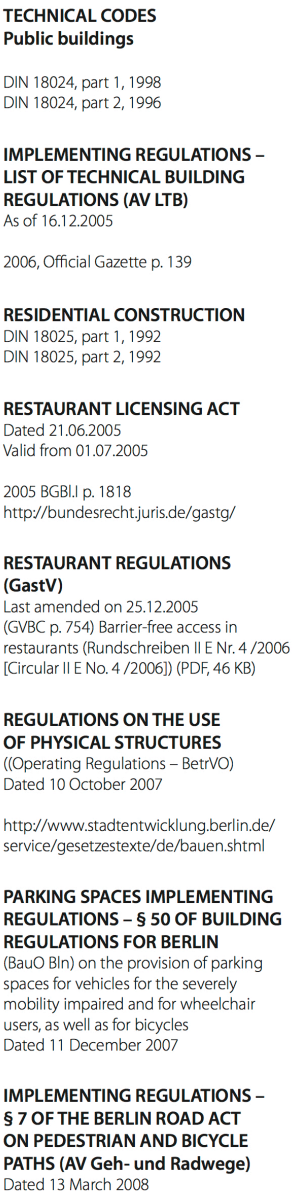 \\
\hline
\end{tabular}

Source: Senate Department for Urban Development and the Environment. (2007). Barrier-free Planning and Construction in Berlin: Principles and Examples. 


\section{REFERENCES}

Access City Award. (2015). Retrieved November 15, 2015, from http://ec.europa.eu/social/main.jsp?catld=1141

Accessibility Directorate of Ontario Ministry of Community and Social Services. (2013). Towards an Accessible Ontario: Accessibility for Ontarians with Disabilities Act, 2005, University of Windsor, Accessibility Awareness Day 2013 [presentation]. Retrieved from http://www1.uwindsor.ca/aad/system/files/MacKillop,\%20Windsor\%20UMarch2013.pdf

Accessibility for Ontarians with Disabilities Act, 2005. Statutes of Ontario (2005, Chapter 11), Retrieved from the Government of Ontario's website: https://www.ontario.ca/laws/statute/05a11

Arnstein, S. R. (1969). A Ladder Of Citizen Participation. Journal of the American Institute of Planners. 35:4. 216-224. DOI: 10.1080/01944366908977225

Biggs, D. (2013, May 5). The Final Frontier: Engaging Vulnerable \& Disadvantaged People in Planning [Webinar]. In Webinar - Engaging Disadvantaged People in Planning. Retrieved from http://metroquest.com/webinar-engaging-vulnerabledisadvantaged-people-in-planning/

Biggs, D. (2016, February 23). Tip of the Iceberg: Seeking Real Accessibility in Community Engagement. Retrieved from http://www.planetizen.com/node/84215

Brookfield Institute (Sponsor). (2015). hack-cessibility-244 [Electronic Image], Retrieved from URL https://www.flickr.com/photos/136584968@N04/21905492463/in/album72157660390022132/.

Center for Universal Design NCSU. (2008). About the Center - Ronald L. Mace. Retrieved April 09, 2016, from https://www.ncsu.edu/ncsu/design/cud/about_us/usronmace.htm

Certified for Access. (2016). FAQs. Retrieved April 01, 2016, from https://www.certifiedforaccess.ca/content/faqs

City of Toronto. (2004). Accessibility Design Guidelines. Toronto, ON: City of Toronto.

City of Torotno. (2011). Toronto named Canada's high tech hub. Retrieved from http://www1.toronto.ca/wps/portal/contentonly?vgnextoid=af71df79b2df6410VgnV CM10000071d60f89RCRD\&nrkey=B6C13EB6848FD0F685257863006BA3AB

European Commission. (2010). Communication From The Commission To The European Parliament, The Council, The European Economic And Social 
Committee And The Committee Of The Regions European Disability Strategy 2010-2020: A Renewed Commitment to a Barrier-Free Europe. Brussels, Belgium: European Commission.

European Commission. (2015). Launch of public consultation on the review of the European Disability Strategy. Retrieved from http://ec.europa.eu/social/main.jsp?langld=en\&catld=1137\&newsld=2421\&further News=yes

Fischer, G. (2011). Understanding, Fostering, and Supporting Cultures of Participation. Interaction, 18(3), 42-53.

Flyvbjerg, B. (1998). Rationality and Power: Democracy in Practice. Chicago IL: University of Chicago.

Forester, J. (1989). Planning in the Face of Power. University of California Press.

Geddes, P. 1968. Cities in evolution; an introduction to the town planning movement and to the study of civics. New York: H. Fertig.

Government of Ontario. (2005). About the Accessibility for Ontarians with Disabilities Act, 2005 (AODA)

Government of Ontario. (2015). The Path to 2025: Ontario's Accessibility Action Plan. Retrieved from the Government of Ontario's website: https://www.ontario.ca/page/path-2025-ontarios-accessibility-action-plan

Human Rights Code. Revised Statutes of Ontario (1990, Chapter H.19). Retrieved from the Government of Ontario's website: https://www.ontario.ca/laws/statute/90h19\#BK19

Hutton, S., Park, P., Park, R., \& Rider, K. (2010). Rights, respect and tokenism: Challenges in self-advocacy. Journal on Developmental Disabilities, 16(1), 109113. Retrieved from http://ezproxy.lib.ryerson.ca/login?url=http://search.proquest.com/docview/751423 848 ? accountid $=13631$

Innes, J. E., \& Booher, D. E. (2004). Reframing Public Participation: Strategies for the 21st Century. Planning Theory \& Practice, 5(4), 419-436.

International Telecommunication Union (ITU). (2013). The ICT Opportunity For $A$ Disability-Inclusive Development Framework. Retrieved from http://www.itu.int/en/action/accessibility/Pages/hlmdd2013.aspx

Jacobs, J. (1961). The Death and Life of Great American Cities. New York: Modern Library. 
Duckworth, K., Molina, E., Graham, A., Harris, J., Jackson, J., and Lewis, T. (2013). Poetic Justice Featuring Drake [Recorded by Kendrick Lamar]. On good kid, m.A.A.d city [Compact Disc]. Santa Monica: Aftermath Entertainment. (2013)

LeGates, R., \& Stout, F. (eds.) (2011a). Engels: The Great Towns (pp. 46-55) in The City Reader. New York: Routledge.

LeGates, R., \& Stout, F. (eds.) (2011b). Howard: Author's Introduction and The TownCountry Magnet (pp. 329-335) in The City Reader. New York: Routledge.

LeGates, R., \& Stout, F. (eds.) (2011c). Olmstead: Public Parks and the Enlargement of Towns (pp. 321-327) in The City Reader. New York: Routledge.

Lord, G. D., \& Blankenberg, N. (2015). Cities, museums and soft power. Arlington, VA: American Alliance of Museums Press

Mace, R. L. (1998). Universal design in housing. Assistive Technology, 10(1), 21-28. doi:10.1080/10400435.1998.10131957

Mather, L. W. (2014). Civic Crafting: The Potential of Minecraft for Municipal Civic Engagement (Major Research Paper). Ryerson University: Toronto

Ministry of Municipal Affairs, Provincial Planning Policy Branch. (2014). Provincial Policy Statement 2014 under the Planning Act, 2011.[Ontario]: Ministry of Municipal Affairs and Housing

Neuman, W. L. (2007). Basics of Social Research: Qualitative and Quantitative Approaches (2nd ed.). Boston, MA: Pearson Education

Neumann, P., \& Uhlenkueken, C. (2001). Assistive Technology and the Barrier-free City: A Case Study from German. Urban Studies, 38(2), 367-376.

Ontario Centres of Excellence (OCE). (2015). Toronto-based social enterprise takes top spot at Parapan Am accessibility tech pitch contest [Press release]. Retrieved from http://www.oce-ontario.org/news-events/media/news-releases/2015/08/11/torontobased-social-enterprise-takes-top-spot-at-parapan-am-accessibility-tech-pitchcontest

Paquette, A. \& Rogojine, V. (2015). Universal Accessibility and the Impact on Design and Planning: 2015 PRO Educational Forum [Slideshow]. Retrieved from http://lin.ca/sites/default/files/attachments/universal-accessibility-impact-on-designand-planning.pdf

PlaceMatters. (2014). Engagement Technology For All: Best Practices for Using Technology in Engaging Underrepresented Communities in Planning. 
Planning Act. Revised Statutes of Ontario (2011, Chapter P.13). Retrieved from the Government of Ontario's website: http://www.elaws.gov.on.ca/html/statutes/english/elaws_statutes_90p13_e.htm

Rittel, H. W., \& Webber, M. M. (1973). Dilemmas in a General Theory of Planning. Policy Sciences, 4, 155-169.

Ross, T. (2013). Advancing Ontario's Accessibility: A Study of Linguistic, Discursive, and Conceptual Barriers. Canadian Journal of Urban Research, 22(1), 126-144.

Salah, H., \& Chung, H. (2013). Towards an Accessibiile Future: Ontario Innovators in Accessibility and Universal Design (Rep.). Retrieved https://www.marsdd.com/wpcontent/uploads/2014/01/Towards-an-Accessible-Future-Ontario-Innovators-inAccessibility-and-Universal-Design1.pdf

Senate Department for Urban Development and the Environment. (2007). Barrier-free Planning and Construction in Berlin: Principles and Examples.

Senate Department for Urban Development and the Environment. (n.d.). City Models of Berlin, Talking City Model in Scale: 1:2000. Retrieved from http://www.stadtentwicklung.berlin.de/planen/stadtmodelle/en/tastmodell_2000.sht $\mathrm{ml}$

Shaw, K. (2014). Kevin Shaw: Design the Inclusive Experience [Video file]. Retrieved from https://youtu.be/zxZ7q0d9bLI

Statistics Berlin Brandenburg (Amtfür Statistik Berlin-Brandenburg). (2015). Die klein Berlin-Statistik 2015.

Technopedia. (n.d.). What is Information and Communications Technology (ICT)? Definition from Techopedia. Retrieved March 28, 2016, from https://www.techopedia.com/definition/24152/information-and-communicationstechnology-ict

Toronto 2015 Pan Am/Parapan Am Games. (2015). About the Parapan Am Games. Retrieved March 13, 2016, from http://www.toronto2015.org/about-us/parapan-amgames

United Nations. (n.d.). Convention on the Rights of Persons with Disabilities. Retrieved from http://www.un.org/disabilities/convention/conventionfull.shtml

WHO. (2007). Global age-friendly cities: A guide. Geneva: World Health Organization 